\title{
Ace-I duplication in Anopheles gambiae: a challenge for malaria control
}

\author{
Luc Djogbénou $^{\dagger 1,2}$, Pierrick Labbé* ${ }^{\dagger 3}$, Fabrice Chandre ${ }^{1}$, Nicole Pasteur ${ }^{4}$ \\ and Mylène Weill ${ }^{4}$
}

\begin{abstract}
Address: ${ }^{1}$ Institut de Recherche pour le Développement, UR 016, 01 BP 4414 RP Cotonou, Benin, ${ }^{2}$ Centre de Recherche Entomologique de Cotonou (CREC), 06 BP 2604 Cotonou, Benin, ${ }^{3}$ Institute of Evolutionary Biology, University of Edinburgh, Edinburgh, UK and

${ }^{4}$ Université Montpellier 2 - CNRS, Institut des Sciences de l'Evolution, Equipe Génétique de l'Adaptation, C.C. 065, Place Eugène Bataillon, 34095 Montpellier, France

E-mail: Luc Djogbénou - Luc.Djogbenou@ird.fr; Pierrick Labbé* - Pierrick.Labbe@ed.ac.uk; Fabrice Chandre - Fabrice.Chandre@ird.fr; Nicole Pasteur - nicole.pasteur@univ-montp2.fr; Mylène Weill - mylene.weill@univ-montp2.fr

${ }^{*}$ Corresponding author †Equal contributors
\end{abstract}

Published: 18 April 2009

Malaria Journal 2009, 8:70 doi: 10.1186/1475-2875-8-70

This article is available from: http://www.malariajournal.com/content/8/I/70

(c) 2009 Djogbénou et al; licensee BioMed Central Ltd.

This is an Open Access article distributed under the terms of the Creative Commons Attribution License (http://creativecommons.org/licenses/by/2.0), which permits unrestricted use, distribution, and reproduction in any medium, provided the original work is properly cited.

Received: 12 December 2008

Accepted: 18 April 2009

\begin{abstract}
Background: Insecticide resistance is a rapid and recent evolutionary phenomenon with serious economic and public health implications. In the mosquito Anopheles gambiae s.s., main vector of malaria, resistance to organophosphates and carbamates is mainly due to a single amino-acid substitution in acetylcholinesterase I (AChEI). This mutation entails a large fitness cost. However, a resistant duplicated allele of the gene encoding AChEI (ace-I), potentially associated to a lower fitness cost, recently appeared in An. gambiae.

Methods: Using molecular phenotype data collected from natural populations from West Africa, the frequency of this duplicated allele was investigated by statistical inference. This method is based on the departure from Hardy-Weinberg phenotypic frequency equilibrium caused by the presence of this new allele.

Results: The duplicated allele, $A g-a c e-I^{D}$, reaches a frequency up to 0.65 in lvory Coast and Burkina Faso, and is potentially present in Benin. A previous study showed that $A g-a c e-I^{D}$, present in both $\mathrm{M}$ and $\mathrm{S}$ molecular forms in different West Africa countries, was generated by a single genetic event. This single origin and its present distribution suggest that this new allele is currently spreading.

Conclusion: The spread of this less costly resistance allele could represent a major threat to public health, as it may impede An. gambiae control strategies, and thus increases the risk of malaria outbreaks.
\end{abstract}

\section{Background}

Since early 1950s, humans have controlled the populations of many agricultural or medical arthropod pests, mostly with chemical insecticides. After years of success, evolutionary adaptations to these new conditions began to occur and resistance spread rapidly; more than 500 species are now resistant to at least one insecticide [1]. Insecticide resistance is a rapid and recent evolutionary phenomenon, providing insight into the processes of adaptation through natural selection, but it has serious 
economic and public health implications. In the arms race between arthropods and humans, the mosquito Anopheles gambiae, the main vector of malaria, seems to have just moved up a gear with the emergence of a resistant duplicated allele of the gene encoding acetylcholinesterase 1 (AChE1).

AChE1 is a critical enzyme in nerve transmission and the target of two of the most commonly used types of insecticides (organophosphates, OPs, and carbamates, CXs). Like several other mosquito species (including Culex pipiens, the well-studied vector of West Nile virus), An. gambiae displays resistance due to a single aminoacid substitution, from a glycine to a serine at the position 119, in the AChE1 catalytic site (G119S)[2]. In C. pipiens, there is direct and indirect evidence that the resistance allele $\left(\right.$ ace- $\left.1^{R}\right)$ entails a large fitness cost, probably due to the mutated AChE1 having a much lower level of activity. Homozygous ace- $1^{R}$ mosquitoes survive in the presence of insecticide, but are rapidly outcompeted in the absence of insecticide (see review in [3]). Heterozygotes are subject to smaller costs than resistant homozygotes in the absence of insecticide. In treated areas, they survive better than susceptible homozygotes, but are less resistant than ace $-1^{R}$ homozygotes. Due to the patchy nature of mosquito control, the generalist heterozygote is advantaged across treated and non-treated areas, although the more specialist resistant and susceptible homozygotes are locally selected in treated and non-treated environments respectively. Moreover, heterozygotes cannot invade due to the segregation burden leading to the loss of the advantage in half of their progeny.

Several duplicated alleles $\left(\right.$ ace $\left.-1^{D}\right)$ have recently appeared, which link a susceptible and a resistant copy of the ace-1 gene on the same chromosome [4]. Duplication thus creates a "permanent heterozygote" allele. The first case of ace-1 gene duplication was recently discovered in An. gambiae [5]. Molecular analysis showed this duplicated allele $\left(A g\right.$-ace- $\left.1^{D}\right)$ to be present at several sites and to have probably spread among the two molecular forms S and M of An. gambiae s.s, by introgression.

Unfortunately, it is not possible to design a simple test for studying the frequency of $A g$-ace- $1^{D}$ due to the lack of features specific to this duplication, as with available genotyping methods carriers of this duplicated allele cannot be distinguished from classical heterozygotes. Thus an indirect method previously developed for $C$. pipiens was used to estimate $A g-a c e-1^{D}$ frequency in the field [6]. The results of this analysis and the potential consequences for An. gambiae population management and on malaria control are discussed.

\section{Methods}

\section{Data collection}

The study area is shown in Figure 1. Both published data $[5,7]$ and data from new samples were used. The date and location of the sampling sites are shown in Table 1. For each locality, several ponds where sampled in an area a few hundred meter-squares to insure a representative sample of the local population.

\section{Molecular analysis}

All samples were collected at the larval stage and reared to adulthood in the laboratory. Genomic DNA was extracted from each field mosquito. The protocol used is a simplified version of Collins et al. [8]: a single mosquito is homogenized in a $1.5 \mathrm{ml}$ Eppendorf tube containing $200 \mu \mathrm{l}$ of CTAB buffer $(100 \mathrm{mM}$ Tris HCL, $\mathrm{pH}$ 8.0, $10 \mathrm{mM}$ EDTA, $1.4 \mathrm{M} \mathrm{NaCl}, 2 \% \mathrm{CTAB}$ ) and incubated at $65^{\circ} \mathrm{C}$ for $5 \mathrm{~min}$; then $200 \mu \mathrm{l}$ of chloroform are added. After centrifugation (room temperature, $5 \mathrm{~min}, 12000 \mathrm{~g}$ ), the supernatant is moved to a fresh tube, $200 \mu \mathrm{l}$ of isopropyl alcohol are added, and the mix is centrifuged again $(12000 \mathrm{~g}, 15 \mathrm{~min})$. After discarding supernatant, the pellet is washed with $70 \%$ ethanol, dried and resuspended in DNAse Free water. The molecular form of each individual was determined by a PCR-based test,

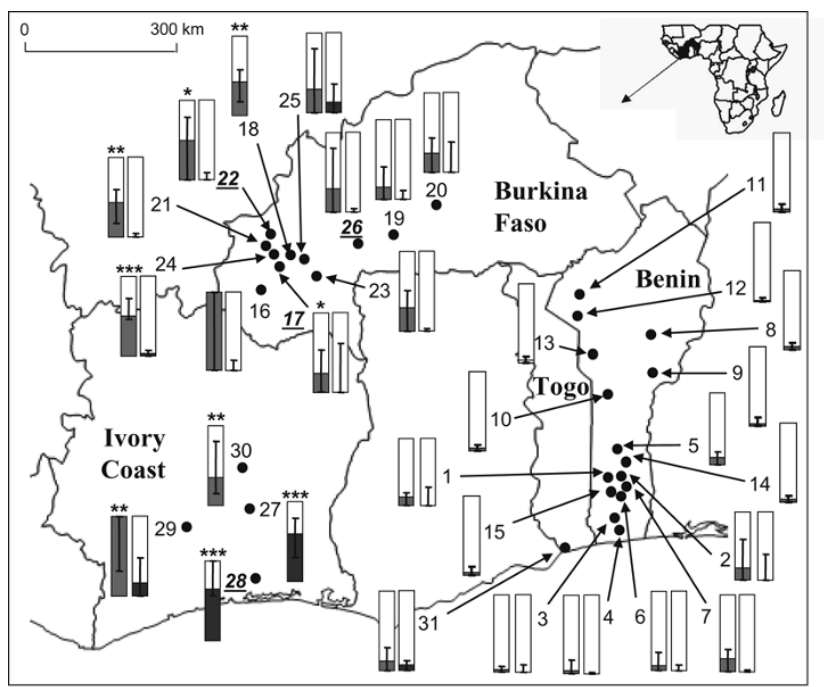

Figure I

Ag-ace- $I^{D}$ frequency in Western Africa. The frequency of $A g$-ace- $I^{D}$ is given for each An. gambiae molecular form: $M$ (red) and $S$ blue). Samples are described in Table I. Samples in which Ag-ace- $I^{D}$ was detected by molecular analysis are bolded and underlined (Table 2). Significant presence of the duplicated allele (before Bonferroni correction, see Methods) is given with * for $P<0.05$, ** for $P<0.01$ and $* * *$ for $P<0.001$. 
Table I: Sample data

\begin{tabular}{|c|c|c|c|c|}
\hline \# & Locality & Country & Sampling date & Ref \\
\hline I & Abomey & Benin & june 06 & [5] \\
\hline 2 & Bohicon & Benin & may 06 & [5] \\
\hline 3 & Houegbo & Benin & apr 06 & This study \\
\hline 4 & Niaouli & Benin & apr 06 & This study \\
\hline 5 & Paouignan & Benin & june 06 & [5] \\
\hline 6 & Zogbodomey & Benin & may 06 & [5] \\
\hline 7 & Cana & Benin & may 06 & This study \\
\hline 8 & Bembereke & Benin & oct-07 & This study \\
\hline 9 & Parakou & Benin & oct-06 & This study \\
\hline 10 & Bassila & Benin & oct-07 & This study \\
\hline II & Tanguieta & Benin & oct-07 & This study \\
\hline 12 & Natitingou & Benin & oct-07 & This study \\
\hline 13 & Djougou & Benin & oct-07 & This study \\
\hline 14 & Dassa & Benin & oct-07 & This study \\
\hline 15 & Savalou & Benin & oct-07 & This study \\
\hline 16 & Darsalamy & Burkina Faso & aug 06 & [7] \\
\hline 17 & Dioulassoba & Burkina Faso & apr 06 & {$[5,7]$} \\
\hline 18 & Kuinima & Burkina Faso & apr 06 & [7] \\
\hline 19 & Mombamba & Burkina Faso & aug 06 & This study \\
\hline 20 & Sabou & Burkina Faso & aug 06 & This study \\
\hline 21 & Samandeni & Burkina Faso & aug 06 & [7] \\
\hline 22 & Séguéré & Burkina Faso & aug 06 & {$[5,7]$} \\
\hline 23 & Soumousso & Burkina Faso & aug 06 & This study \\
\hline 24 & Vallée du Kou & Burkina Faso & apr 05 & [7] \\
\hline 25 & Yegueresso & Burkina Faso & aug 06 & [7] \\
\hline 26 & Boromo & Burkina Faso & aug 06 & [5] \\
\hline 27 & Toumodi & Ivory Coast & sept-04 & [5] \\
\hline 28 & Niamoue & Ivory Coast & sept-04 & [5] \\
\hline 29 & Toumbokro & Ivory Coast & sept-04 & [5] \\
\hline 30 & Yaokoffikro & Ivory Coast & sept-04 & [5] \\
\hline 31 & Lomé & Togo & march 05 & This study \\
\hline
\end{tabular}

For each population shown in Fig. I (the corresponding number is indicated in column \#), the country, sampling date and study of reference are given.

as described in [9]. The ace-1 genotype was assessed by RFLP analysis (see $[5,7]$ ).

\section{Statistical analyses}

The presence of a duplicated allele causes an apparent excess of heterozygous [RS] phenotypes and thus a departure from the Hardy-Weinberg proportions expected with two alleles only $\left(\right.$ ace $-1^{R}$ and ace-1 $\left.1^{S}\right)$ [6]. This departure is related to the frequency of the duplicated allele and was used to estimate $A g$-ace- $1^{D}$ frequency in An. gambiae populations. The presence of Ag-ace- $1^{D}$ was investigated by fitting two models to the phenotypic data for each sample independently: i) a two-alleles-only model (ace- $1^{R}$ and $a c e-1^{S}$ ) and ii) a three-allele model, adding the duplicated allele $A g$-ace $1^{D}$. The frequency of the duplicated allele was estimated from the excess of heterozygotes observed in each sample, assuming that this excess was due exclusively to the presence of $A g$-ace- $1^{D}$ [6]. This method is not as accurate as a direct identification of genotypes, but the two methods gave highly concordant results for field samples of C. pipiens [6]. This indirect estimate of
$A g$-ace $1^{D}$ frequency may be biased if the genotypes are not in Hardy-Weinberg equilibrium. However, such a bias is not expected as An. gambiae populations large size prevents drift and as no overdominance leading to heterozygote excess was ever found for resistance [10]. Moreover, previous studies of neutral markers in An. gambiae show either no departure from Hardy-Weinberg expectations or a deficit in heterozygotes, but never an excess, ensuring that this method is conservative (e.g. $[11,12])$.

For each sample, the expected phenotypic distributions were calculated for the S and $\mathrm{M}$ molecular forms, using allelic distributions and assuming the ace-1 locus to be at Hardy-Weinberg equilibrium. Phenotype was considered to be a three-state random variable ([RR] corresponding to $(\mathrm{R} / \mathrm{R})$ genotype, $[\mathrm{RS}]$ corresponding to $(\mathrm{R} / \mathrm{S}),(\mathrm{D} / \mathrm{S})$, $(D / R)$ and $(D / D)$ genotypes, and [SS] corresponding to (S/S) genotype). The log-likelihood of a sample was calculated from the phenotypic multinomial distribution. Let $n_{i j}$ and $f_{i j}$ be the observed number and expected frequency of individuals with phenotype $i$ in population $j$, respectively. The $\log$ likelihood $L$ of observing all the data is proportional to

$$
L_{j}=\sum_{i} n_{i j} \ln \left(f_{i j}\right)
$$

$L$ was maximized, using the Metropolis algorithm $[13,14]$. Model likelihoods were compared using F-tests: by construction, the three-allele model has a higher likelihood, but the presence of the duplication is considered to be confirmed only if the likelihood of this model is significantly higher than that of the two-allele model (significant $P$-value). The support limits for the frequency of each allele were also estimated. Finally, the $P$-values obtained were corrected for multiple testing, using Hommel's sequential Bonferroni correction [15]. The different samples from each country were also pooled to get a higher statistical power at a larger geographical scale (Table 2), and the same analysis as for independent collection sites has been done. As pooling data from different populations is likely to result in a heterozygote deficit (Wahlund effect), this analysis is likely to underestimate any global excess of heterozygotes [6], making the detection of such excess more significant.

\section{Results and discussion}

The frequency of the recently discovered duplicated allele of the ace-1 gene in An. gambiae, Ag-ace-1 ${ }^{D}$, was investigated in natural populations from West Africa by considering the departure from Hardy-Weinberg proportions caused by its presence [6]. 


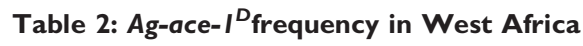

\begin{tabular}{|c|c|c|c|c|c|c|c|c|c|c|c|}
\hline \multirow[b]{2}{*}{ \# } & \multirow[b]{2}{*}{ Locality } & \multirow[b]{2}{*}{$\mathbf{N}$} & \multicolumn{4}{|c|}{$M$ form } & \multirow[b]{2}{*}{$\mathbf{N}$} & \multicolumn{4}{|c|}{$S$ form } \\
\hline & & & $\mathbf{R}$ & $\mathbf{S}$ & D & $P$-value & & $\mathbf{R}$ & $\mathbf{S}$ & D & $P$-value \\
\hline I & Abomey & 3 & - & I & - & - & 68 & 0 & 0.87 & 0.13 & $0.144^{N S}$ \\
\hline 2 & Bohicon & 2 & - & I & - & - & 3 & 0 & 0.82 & 0.18 & $0.654^{\mathrm{NS}}$ \\
\hline 3 & Houegbo & 9 & - & I & - & - & 62 & 0 & 0.97 & 0.03 & $0.715^{\mathrm{NS}}$ \\
\hline 4 & Niaouli & 50 & - & 1 & - & - & 12 & 0 & 0.96 & 0.04 & $0.835^{\mathrm{NS}}$ \\
\hline 5 & Paouignan & 0 & - & - & - & - & 41 & 0 & 0.9 & 0.1 & $0.352^{\mathrm{NS}}$ \\
\hline 6 & Zogbodomey & 13 & - & I & - & - & 9 & 0 & 0.94 & 0.06 & $0.808^{\mathrm{NS}}$ \\
\hline 7 & Cana & 38 & - & I & - & - & 26 & 0 & 0.83 & 0.17 & $0.227^{\mathrm{NS}}$ \\
\hline 8 & Bembereke & 0 & - & - & - & - & 62 & 0 & 0.96 & 0.04 & $0.647^{\mathrm{NS}}$ \\
\hline 9 & Parakou & 0 & - & - & - & - & 20 & 0 & 0.97 & 0.03 & $0.873^{\mathrm{NS}}$ \\
\hline 10 & Bassila & 0 & - & - & - & - & 76 & 0 & 0.97 & 0.03 & $0.68^{\mathrm{NS}}$ \\
\hline II & Tanguieta & 0 & - & - & - & - & 47 & 0 & 0.96 & 0.04 & $0.673^{\mathrm{NS}}$ \\
\hline 12 & Natitingou & 0 & - & - & - & - & 48 & 0 & 0.99 & 0.01 & $0.918^{N S}$ \\
\hline 13 & Djougou & 0 & - & - & - & - & 46 & 0 & 0.97 & 0.03 & $0.750^{\mathrm{NS}}$ \\
\hline 14 & Dassa & 0 & - & - & - & - & 64 & 0 & 0.96 & 0.04 & $0.652^{\mathrm{NS}}$ \\
\hline \multirow[t]{2}{*}{15} & Savalou & 0 & - & - & - & - & 29 & 0 & 0.96 & 0.04 & $0.789^{\mathrm{NS}}$ \\
\hline & Total Bénin & 115 & - & I & - & - & 221 & 0 & 0.91 & 0.09 & $0.052^{\mathrm{NS}}$ \\
\hline 16 & Darsalamy & 7 & - & I & - & - & 2 & 0 & 0 & 1 & $0.096^{\mathrm{NS}}$ \\
\hline 17 & Dioulassoba & I & - & I & - & - & 23 & 0.21 & 0.55 & 0.24 & $0.044^{*}$ \\
\hline 18 & Kuinima & 0 & - & - & - & - & 27 & 0 & 0.58 & 0.42 & $0.002 * *$ \\
\hline 19 & Mombamba & 8 & - & I & - & - & 7 & 0 & 0.85 & 0.15 & $0.563^{\mathrm{NS}}$ \\
\hline 20 & Sabou & 2 & - & I & - & - & 14 & 0 & 0.76 & 0.24 & $0.198^{N S}$ \\
\hline 21 & Samandeni & 20 & - & I & - & - & 25 & 0 & 0.57 & 0.43 & $0.002^{* * *}$ \\
\hline 22 & Séguéré & 10 & - & I & - & - & 8 & 0 & 0.5 & 0.5 & $0.049 *$ \\
\hline 23 & Soumousso & 32 & - & 1 & - & - & 12 & 0 & 0.71 & 0.29 & $0.153^{\mathrm{NS}}$ \\
\hline 24 & Vallée du Kou & 86 & 0 & 0.96 & 0.04 & $0.64 I^{\mathrm{NS}}$ & 80 & 0.16 & 0.34 & 0.51 & $0.000 * * *$ \\
\hline 25 & Yegueresso & 8 & 0 & 0.87 & 0.13 & $0.592^{\mathrm{NS}}$ & 2 & 0 & 0.71 & 0.29 & $0.560^{\mathrm{NS}}$ \\
\hline \multirow[t]{2}{*}{26} & Boromo & 38 & 0.05 & 0.95 & 0 & $1.000^{\mathrm{NS}}$ & 2 & 0 & 0.71 & 0.29 & $0.560^{\mathrm{NS}}$ \\
\hline & Total Burkina Faso & 212 & 0.03 & 0.97 & 0 & $1.000^{\mathrm{NS}}$ & 202 & 0.12 & 0.53 & 0.35 & 0.000 *** \\
\hline 27 & Toumodi & 18 & 0 & 0.41 & 0.59 & $0.00 I^{* * *}$ & 0 & - & - & - & - \\
\hline 28 & Niamoue & 24 & 0.35 & 0 & 0.65 & $0.000 * * *$ & 0 & - & - & - & - \\
\hline 29 & Toumbokro & 19 & 0.23 & 0.61 & 0.16 & $0.195^{\mathrm{NS}}$ & 5 & 0 & 0 & 1 & $0.008 * *$ \\
\hline \multirow[t]{2}{*}{30} & Yaokoffikro & 0 & - & - & - & - & 19 & 0.32 & 0.32 & 0.35 & $0.009 * *$ \\
\hline & Total Ivory Coast & 61 & 0.26 & 0.4 & 0.34 & $0.000 * * *$ & 24 & 0.29 & 0.29 & 0.42 & $0.001 * * *$ \\
\hline 31 & Lomé (Togo) & 73 & 0 & 0.93 & 0.07 & $0.391^{\mathrm{NS}}$ & 13 & 0 & 0.88 & 0.12 & $0.531^{\mathrm{NS}}$ \\
\hline
\end{tabular}

For each population sampled, the number of mosquitoes of each of the $S$ and $M$ molecular forms of An. gambiae is given, together with the estimated frequency of the various alleles: $\mathrm{R}, \mathrm{S}$ and $\mathrm{D}$ for $a c e-I^{R}$, ace- $I^{S}$ and ace- $I^{\mathrm{D}}$, respectively. A global estimation is also presented for each country sampled. The populations in italics are those in which Ag-ace- $I^{D}$ has been identified by molecular analysis [5]. Finally, the $p$-value for the test for the presence of ace- $I^{D}$ is also given for each population (see Methods), with ${ }^{N S}$ for $P \geq 0.05$, * for $P<0.05$, ** for $P<0.01$ and $* * *$ for $P<0.001$ (except when no estimate was possible, i.e. when all the mosquitoes of a sample were susceptible). The $P$-values that remained significant after Bonferroni correction (see methods) are presented in bold; $P$-values no longer significant after Bonferroni correction are shown in italics.

Figure 1 shows the predicted spatial distribution of $A g$ ace $-1^{D}$ in the $S$ and $M$ forms of An. gambiae, as shown by previous molecular investigations and analyses of heterozygote excess. The probability of $A g$-ace- $1^{D}$ being present was significant in nine samples (five after Bonferroni correction) from Ivory Coast (four samples) and Burkina Faso (five samples), in both $M$ (two samples) and $S$ (seven samples) molecular forms of An. gambiae (Figure 1 and Table 2). In these samples, the frequency of $A g-a c e-1^{D}$ was up to 0.65 , with the lowest significant frequency being 0.24 , consistent with the expected highly conservative output of the method used. Indeed, this method will detect low frequencies only in large samples; for example, $A g$-ace- $1^{D}$ was not detected with this method in one of the analysed populations
(Boromo, population \#26, Table 2), whereas molecular methods proved this duplication to be present [5]. The frequency and the geographic distribution of this duplication are therefore probably underestimated. For example, the analysis of each Benin population independently did not provide any indication supporting the presence of the duplication in this country (Figure 1 and Table 2). Nevertheless, the pooled analysis yields a $P$-value of 0.052 , which points toward the potential presence of $A g-a c e-1^{D}$ as this method underestimate the excess of heterozygotes and thus its frequency. However, more data are required to confirm the presence of the duplicated allele in Benin (Table 2). The complete lack of variation of the $A g-a c e-1^{D}$ sequence over several countries [5] indicates that this allele was generated by 
a single genetic event and its current distribution suggests that it is probably spreading.

Unfortunately, the spread of this new resistance allele poses a potential major threat to public health, as $A n$. gambiae is the main vector of malaria. Indeed, several studies of a similar allele in C. pipiens have indicated that the duplication entails a lower fitness cost than the single-copy resistance gene, ace- $1^{R}[4,6]$ (but see [16]). This is probably also the case for An. gambiae, as the mutated AChE1 gene is also associated with a strong decrease in enzyme activity [17]. The presence and spread of the $A g$-ace- $1^{D}$ allele may greatly impede $A n$. gambiae control strategies designed to maintain resistance alleles at low frequencies through the use of different insecticides with no cross-resistance in a mosaic or rotation strategy. It has been clearly demonstrated $[18,19]$ that the efficiency of such strategies increases with the fitness cost of resistance.

\section{Conclusion}

Insecticides for controlling malaria vectors are a major weapon in the battle between humans and malaria. Unfortunately, these insecticides exert strong selection pressure on vector populations, causing the spread of resistance genes, such as the resistance allele observed at the ace-1 locus in An. gambiae. The long-term use of an insecticide promotes the selection of new resistant variants, with a high risk of selecting a low (or null)cost variant. The ace-1 duplicated allele recently appeared in An. gambiae is probably an example of such a low-cost variant. It is shown here that the presence of this duplicated allele, known from the molecular analysis of a few mosquitoes in some samples from Burkina Faso and Ivory Coast [5] is largely distributed in several countries of Western Africa, sometimes at high frequencies, and that it is probably spreading.

To prevent such spreads of resistance genes, it is crucial to develop the largest possible number of complementary means of control (e.g. larval insecticides, mosquito nets, biological agents, etc.) and to use them wisely. However, the emergence of ace-1 duplication in natural populations of An. gambiae, has just given mosquitoes the edge in this particular battle, seriously undermining our efforts to control vector populations and increasing the risk of malaria outbreaks.

\section{Competing interests}

The authors declare that they have no competing interests.

\section{Authors' contributions}

LD designed the study, acquired the data and wrote the manuscript. PL analysed the data and wrote the manuscript. NP, FC and MW contributed to the design of the study and for draft and revision of the manuscript. All authors read and approved the final manuscript.

\section{Acknowledgements}

This work was funded in part by the ANR Morevol Sante-Environnement (Ministère délégué à la Recherche) and in part by the Institut de Recherche Pour le Développement (IRD). It is the contribution 2009-025 of the Institut des Sciences de L'Evolution de Montpellier (ISEM, UMR CNRSUM2 5554).

\section{References}

I. Bills P: A new database of pesticide resistant insects and mites (Arthropods). Pesticide notes 200I, I4:2-4.

2. Weill M, Lutfalla G, Mogensen K, Chandre F, Berthomieu A Berticat C, Pasteur N, Philips A, Fort P and Raymond M: Insecticide resistance in mosquito vectors. Nature 2003, 423:136-I37.

3. Weill $M$, Labbé $P$, Duron $O$, Pasteur N, Fort $P$ and Raymond $M$ : Insecticide resistance in the mosquito Culex pipiens : towards an understanding of the evolution of ace genes. Insect evolutionary ecology Oxon, UK: CABI publishing: Fellowes MDE, Holloway GJ, Rolff J 2005.

4. Labbé $P$, Berthomieu $A$, Berticat $C$, Alout $H$, Raymond $M$, Lenormand $T$ and Weill $M$ : Independent duplications of the acetylcholinesterase gene conferring insecticide resistance in the mosquito Culex pipiens. Mol Biol Evol 2007, 24: I056-I 067.

5. Djogbénou L, Chandre F, Berthomieu A, Dabire R, Koffi A, Alout H and Weill M: Evidence of introgression of the ace- $I{ }^{R}$ mutation and of the ace-I duplication in West African Anopheles gambiae s. s. PLOS ONE 2008, 3:e2172.

6. Lenormand $T$, Guillemaud $T$, Bourguet $D$ and Raymond $M$ : Appearance and sweep of a gene duplication: adaptive response and potential for new functions in the mosquito Culex pipiens . Evolution 1998, 52:1705-I712.

7. Djogbénou L, Dabire R, Diabate A, Kengne $P$, Akogbeto M, Hougard JM and Chandre F: Identification and geographic distribution of the ace- $I^{R}$ mutation in the malaria vector Anopheles gambiae in South-Western Burkina Faso, West Africa. Am J Trop Med Hyg 2008, 78:298-302.

8. Collins FH, Mendez MA, Rasmussen MO, Mehaffey PC, Besansky NJ and Finnerty V: A ribosomal RNA gene probe differentiates member species of the Anopheles gambiae complex. Am J Trop Med Hyg 1987, 37:37-4I.

9. Favia G, Torre Ad, Bagayoko M, Lanfrancotti A, Sagnon NF, Touré YT and Coluzzi M: Molecular identification of sympatric chromosomal forms of Anopheles gambiae and further evidence of their reproductive isolation. Insect Mol Biol I997, 6:377-383.

10. Djogbénou L, Weill M, Hougard JM, Raymond M, Akogbéto $M$ and Chandre F: Characterization of Insensitive Acetylcholinesterase (ace- ${ }^{R}$ ) in Anopheles gambiae (Diptera: Culicidae): Resistance Levels and Dominance. J Med Entomol 2007, 44:805-810.

II. Lanzaro GC, Touré YT, Carnahan J, Zheng L, Dolo G, Traoré S, Petrarca V, Vernick KD and Taylor CE: Complexities in the genetic structure of Anopheles gambiae populations in west Africa as revealed by microsatellite DNA analysis. PNAS 1998, 95: | 4260-| 4265 .

12. Lehmann T, Hawley WA, Kamau L, Fontenille D, Simard F and Collins FH: Genetic differentiation of Anopheles gambiae populations from East and West Africa: comparison of microsatellite and allozyme loci. Heredity 1996, 77:192-200.

13. Labbé $P$, Lenormand $T$ and Raymond $M$ : On the worldwide spread of an insecticide resistance gene: a role for local selection. J Evol Biol 2005, I 8: |47|-|484. 
14. Lenormand $\mathrm{T}$, Bourguet $\mathrm{D}$, Guillemaud $\mathrm{T}$ and Raymond $\mathrm{M}$ : Tracking the evolution of insecticide resistance in the mosquito Culex pipiens . Nature 1999, 400:86I-864.

I5. Hommel G: A stagewise rejective multiple test procedure based on a modified Bonferroni test. Biometrika 1988, 75:383-386.

16. Labbé P, Berticat C, Berthomieu A, Unal S, Bernard C, Weill M and Lenormand $\mathrm{T}$ : Forty years of erratic insecticide resistance evolution in the mosquito Culex pipiens . PLoS Genetics 2007, 3: e205.

17. Alout $H$, Djogbenou L, Berticat C, Chandre $F$ and Weill M: Comparison of Anopheles gambiae and Culex pipiens acetycholinesterase I biochemical properties. Comp Biochem Physiol B-Biochem Mol Biol 2008, I 50:27I-277.

18. Carrière $Y$, Deland J-P, Roff DA and Vincent C: Life-history cost associated with the evolution of insecticide resistance. Proc $R$ Soc Lond B 1994, 258:35-40.

19. Lenormand $T$ and Raymond $M$ : Resistance management: the stable zone strategy. Proc R Soc Lond B 1998, 265:1985-1990.

Publish with BioMed Central and every scientist can read your work free of charge

"BioMed Central will be the most significant development for disseminating the results of biomedical research in our lifetime. "

Sir Paul Nurse, Cancer Research UK

Your research papers will be:

- available free of charge to the entire biomedical community

- peer reviewed and published immediately upon acceptance

- cited in PubMed and archived on PubMed Central

- yours - you keep the copyright

Submit your manuscript here:

http://www.biomedcentral.com/info/publishing_adv.asp
BioMedcentral 